\section{EDUCACIÓN Y COMPROMISO: LAS UNIVERSIDADES JESUITAS EN CENTROAMÉRICA}

\author{
Francisco Javier Gómez Díez \\ Universidad Francisco de Vitoria \\ j.gomez.prof@ufv.es
}

\section{EDUCATION AND COMMITMENT: JESUIT UNIVERSITIES IN CENTRAL AMERICA}

Cómo citar este artículo/Citation: Gómez Díez, F. J. (2016). Educación y compromiso: las universidades jesuitas en Centroamérica. Arbor, 192 (782): a366. doi: http://dx.doi. org/10.3989/arbor.2016.782n6011

Recibido: 04 noviembre 2014. Aceptado: 25 agosto 2015.

RESUMEN: Este artículo analiza a partir, muy especialmente, de las declaraciones públicas de sus responsables, cómo han definido las universidades jesuitas centroamericanas su misión, con la intención de intentar explicar por qué surge en conflicto con el inicial objetivo fundacional de las universidades y, al tiempo, considerar los límites y contradicciones de este esfuerzo.

PALABRAS CLAVE: Universidad; Centroamérica; Compañía de Jesús; Religión y política; Teología de la liberación.
Copyright: (c) 2016 CSIC. Este es un artículo de acceso abierto distribuido bajo los términos de la licencia Creative Commons Attribution (CC BY) España 3.0.

ABSTRACT: An analysis of how Central American Jesuit Universities have defined their mission, with a particular focus on the public declarations of their leading figures. The aim is to explain why this mission contradicts the objectives initially established by these universities, while pointing out the limits and contradictions involved.

KEYWORDS: University; Central America; Society of Jesus; Religion and Politics; Liberation Theology. 
Cuando la Viceprovincia Centroamericana de la Compañía de Jesús, erigida en 1936, se independizó de Castilla, en 1958, superaba los 150 sujetos y contaba, entre otros centros, con cuatro colegios, una academia gratuita de formación profesional y cinco escuelas primarias gratuitas. (Gómez Díez, 1996) Pretendía, además, abrir una universidad, con facultades en tres países: El Salvador, Guatemala y Nicaragua. En un momento de optimismo desarroIlista y esperanza puesta en la colaboración con el Estado, sería la culminación de un éxito - la consolidación de la Compañía en Centroamérica- y, al mismo tiempo, una institución de carácter regional, que contribuyera a la integración formando profesionales y dirigentes políticos para el naciente Mercado Común Centroamericano.

Diversos problemas legales y resistencias de carácter nacionalista fragmentaron el proyecto, naciendo tres universidades independientes: en 1961 la Universidad Centroamericana (UCA) en Nicaragua; en 1962 la Universidad Rafael Landívar (URL), en Guatemala, y en 1965 la Universidad Centroamericana José Simeón Cañas (USC), en el Salvador. En su origen habían confluido el antiguo interés de los jesuitas por ampliar sus actividades en el mundo universitario ${ }^{1}$ y los deseos de diversos grupos de padres que, tras matricular a sus hijos en colegios privados, deseaban que se estableciera una universidad semejante; familias pudientes que no querían o no podían enviar a sus hijos a estudiar al extranjero y deseaban ver satisfecha su necesidad de cualificación, en una época de exitoso desarrollismo, lejos de las universidades públicas, de cuya calidad dudaban, al tiempo que se hacía cada vez más presente en ellas la politización izquierdista.

Con el decidido apoyo de la élite empresarial, la Compañía abre tres universidades contra el monopolio, y pese a la resistencia, de la universidad pública. Universidades que prolongan una larga tradición educativa, se definen apolíticas y se caracterizan por un elitismo profesionalizante mitigado. Desde el principio la USC se definió como corporación no lucrativa de utilidad pública y buscó en José Simeón Cañas - prócer emancipador de los esclavos - un símbolo para un proyecto. Al igual que las otras dos, define sus objetivos en pro del desarrollo económico y social de Centroamérica, multiplicando las carreras técnicas y las becas, proclamando un espíritu de colaboración con el Estado, cuyas universidades tenían dificultades para satisfacer la creciente demanda formativa. Según el P. Florentino Idoate, buscaban formar hombres de personalidad fuerte, espíritu de investigación, deseo de verdad y preocupación por el bien social, hombres privilegiados que, por haber recibido más cultura, deberían ser guías natos de los demás (Mantilla, 1965).

Pese al esfuerzo inicial por mitigar el elitismo, no cabe menospreciar la transformación posterior. En pocos años - olvidemos, por un momento, la diferencia entre las tres universidades - van a redefinir su misión: "contribuir universitariamente al diagnóstico de la real situación del país, al análisis de las causas que motivan esa situación, a su enjuiciamiento crítico y a la propuesta de soluciones eficaces. Una situación que no es sólo de subdesarrollo sino de positiva injusticia. La universidad, por tanto, no puede no estar por un urgente y profundo cambio social" (Consejo Superior Universitario de la USC, 1973).

El cambio no fue accidental, sino esencial y conflictivo. Respondía al dinamismo de la vocación universitaria, a la inspiración cristiana y a los acontecimientos. ¿Qué estaba pasando?

\section{FACTORES DE TRANSFORMACIÓN DEL PROYECTO INICIAL}

Mientras el panorama internacional se veía marcado por el creciente influjo de la ideología comunista, el atractivo de la experiencia cubana, las Ilamadas a la distensión, la popularidad de la teoría de la dependencia y, tras el fracaso de la Alianza para el Progreso, el cuestionamiento de la imagen internacional de EE.UU., y el centroamericano por las transformaciones impulsadas por las políticas desarrollistas y las limitaciones sociales de éstas, la iglesia vive una profunda transformación. Había implementado, desde los años treinta en Centroamérica y, años antes, en otras repúblicas, un esfuerzo de reconstrucción institucional para recuperar el espacio social que el triunfo liberal le había arrebatado, convencida de que, en la medida en la que pudiera actuar con libertad, el pueblo, profundamente católico, respondería adecuadamente. La mejoría fue muy significativa, y la Viceprovincia jesuita centroamericana lo manifiesta, pero, ya a finales de los años cincuenta, la Iglesia empezó a interrogarse sobre el acierto de las líneas seguidas. La Acción Católica fue lo más cuestionado², pero no lo único; los sindicatos cristianos, las mismas obras de caridad y los colegios y universidades sufren una suerte parecida.

Desde 1930 se había dado una profunda transformación en la estructura demográfica americana, con un significativo aumento de la población urbana que, al tiempo que incrementó o hizo más visible la po- 
breza, planteó a la Iglesia el problema de cómo mantener la lealtad de una población de cuyo catolicismo nadie había dudado hasta entonces. Mientras en las ciudades ganan apoyos los partidos de izquierdas y crecen espectacularmente los fieles protestantes y pentecostales, se multiplica la sensación de inseguridad en el seno de la Iglesia católica, cuando la asistencia a misa desciende y siguen escaseando los agentes de pastoral.

La consolidación institucional de la Iglesia y la mejoría de sus relaciones con los gobiernos introdujeron un elemento de responsabilidad ante la realidad social. La crisis no se generó directamente en la frustración del reformismo basado en la movilización del laicado católico, sino en la aparición de un sentimiento de responsabilidad, que había sido totalmente extraño a la generación de 1930: una Iglesia que se sentía débil, perseguida ${ }^{3}$, impotente $y$, por tanto, irresponsable de la situación social. La época de las persecuciones parece superada y la Iglesia, que impulsada por su debilidad y su marginación había buscado el entendimiento con los gobiernos, constata los frustrantes resultados de esta actitud y los inconvenientes de vincularse en exceso a éstos.

Habría que rastrear, hasta dónde $-y$ por qué razones-, se remonta, en la edad contemporánea, el cuestionamiento de los ministerios educativos; sus raíces son profundas. "No faltan - escribe el P. Janssens en 1947- quienes dudan de que conserve en nuestros días tan difíciles este ministerio toda su eficacia y si no convendría más bien, dejando o quitando importancia a los colegios, entregarse por completo al apostolado más directo, particularmente entre los obreros". Estas dudas y tensiones se reflejan en el Survey centroamericano ${ }^{4}$, donde destaca especialmente una llamada al compromiso social y se insiste en el "aburguesamiento" que padece la Compañía. Hecho que debe relacionarse con una sensación de fracaso ante las actividades tradicionales. Se critican las actitudes y los compromisos que tradicionalmente se habían mantenido y, sobre todo, un conjunto de obras que privaban de libertad e impedían luchar por los más necesitados. La amplia actividad educativa, que ocupaba a la mitad de los padres, estaba lejos de satisfacerles: calificaron los colegios de exclusivistas, "de ricos y para ricos"; creían que no estaban formando líderes sociales ni movilizando al laicado y, como resultado, habían fracasado tanto en el fomento de las vocaciones sacerdotales como en la organización de actividades sociales. Las clases altas "no han de ser - se afirma en el Survey - hoy los agentes de transforma- ción y apenas lo han sido nunca"; todo un sistema de trabajo que se había basado en la concepción contraria debía cambiar o desaparecer. La Compañía se sentía responsable de colaborar en el mantenimiento de un estado de injusticia y de haber justificado a los poderosos sus prejuicios de clase. Vistos los resultados, lo que anteriormente se había considerado timbre de orgullo: atraer y formar a la buena alta sociedad ${ }^{5}$, se volvió inaceptable.

La I Conferencia General del Episcopado Latinoamericano (1955), junto al establecimiento de la CELAM, constató todos estos problemas: el alejamiento del pueblo; las dudas sobre la educación católica; que las asociaciones de acción católica no estaban dando todo lo que de ellas se había esperado; que el sindicalismo escapaba a la inspiración cristiana. Mons. Manuel Larraín afirmó que el porvenir de la Iglesia estaba subordinado a la solución cristiana del problema social y la Conferencia, mientras advirtió sobre las injusticias y el subdesarrollo, llamó a los católicos a participar - cosa que hasta entonces habían hecho en escasa medida - en su resolución.

Si el Vaticano II planteó una nueva forma de relación entre la Iglesia y la Sociedad, donde la primera acepta ser una institución sin privilegios en una sociedad pluralista, iniciándose una reconciliación crítica con la sociedad moderna, Juan XXIII y Pablo VI pusieron su interés en el Tercer Mundo y en la urgencia de enfrentarse a la injusticia. Populorum progressio, pensada sobre todo para América Latina y África, constituye una llamada a favor del desarrollo urgente e integral del hombre y de la humanidad. Mientras las amonestaciones más severas las dirige contra los países ricos y los grupos sociales más acomodados, propone a las instituciones eclesiásticas una mayor pobreza y un acercamiento activo a los marginados.

La llamada conciliar a la renovación, cayó en terreno propicio, tanto en América como en la Compañía.

En 1968 se reunió en Medellín la /l Conferencia General del Episcopado Latinoamericano. Con la defensa de la fe, la preocupación de fondo es la solidaridad radical de la Iglesia con los oprimidos. El episcopado siente que es urgente transformar las estructuras sociales, pero teme y denuncia los riesgos que estas transformaciones comportan, tanto contra la sociedad - violencia, factores negativos del desarrollo económico, etc. - como contra la Iglesia - en su ortodoxia y en su unidad.

Tres ideas de la Conferencia son capitales para entender la evolución de las universidades jesuitas: 
- América está bajo el signo de la rápida transformación; los cambios suceden, y de no hacerles frente a tiempo, la Iglesia no podrá cumplir su misión; la tarea se presenta como urgente.

- La misión única de la Iglesia es de orden religioso, pero invade la totalidad del hombre, pues hay una conexión intrínseca entre la construcción de un mundo mejor y el crecimiento del Reino de Dios en la tierra.

- Reivindicando la labor educativa de la Iglesia, exhorta a su renovación dentro de la línea del Vaticano II y señala la ineludible responsabilidad de formar hombres para transformar las estructuras.

La Compañía, sintiendo esta necesidad de renovación, puso en marcha un proceso de respuesta, estudiado recientemente por Urbano Valero, quien presenta, desde el decreto 4 de la Congregación General 310 , la conciencia jesuita de que la Compañía debe estar refundándose permanente para poder ser fiel a sí misma y servir al mundo (Valero Agúndez, 2012). Si el P. General J. B. Janssens tuvo claro tanto los cambios, sociales y eclesiales, como la necesidad de convocar una congregación general en cuanto acabase el Vaticano II, años después, el P. Kolvenbach explica el resultado: "Es justamente esta entrega, este esfuerzo por responder a las exigencias de la Iglesia indicadas por el Santo Padre lo que ha transformado la Compañía en los últimos tiempos. Nuestro compromiso por llevar a la práctica los documentos del Vaticano II han sacudido la Compañía hasta sus raíces, igual que la fidelidad al concilio de Trento modificó profundamente la Compañía poco después de su fundación. Otra razón del cambio de la Compañía de Jesús es su tradicional inserción en el corazón del mundo: las rápidas transformaciones ocurridas en la historia han supuesto cambios profundos también en nuestra orden" (Kolvenbach, 1991, p. 105).

La Congregación General 31ㅇp propone, en consonancia con el Concilio, "adaptar todos los aspectos de su vida y misión... a las exigencias históricas del momento, manteniendo, en fidelidad a la gracia de los orígenes, lo que, por principio, debe ser considerado como permanente e inmutable y dejando caer cuanto con el tiempo se hubiera mostrado obsoleto e inservible". Así lo explicita Kolvenbach, ya en la 34: "De ser fiel a sí misma... la Compañía tendría que estar y haber estado siempre en proceso o, por lo menos, en actitud de renovación acomodada, es decir, de búsqueda de una respuesta, cada vez más afinada y certera a lo que Dios ha ido pidiendo y pide de ella en las circunstancias cambiantes de la historia" (Valero Agúndez, 2012, p. 11 y p. 40). Significativamente, el análisis de John W. O'Malley se convertirá en la interpretación más extendida entre los jesuitas de la figura de Ignacio: un líder capaz de tomar decisiones, con "la habilidad para ver cómo, en una coyuntura dada, es más consecuente con el objetivo propuesto el cambiar que el persistir en la misma dirección" (O’Malley, 1993, p. 454).

Una preocupación central fue establecer los ministerios propios de la Compañía, algo que ya había interesado a los padres Ledóchowski y, sobre todo, Janssens. Consciente de que las circunstancias y exigencias habían cambiado y dudando de que el fruto del trabajo hubiera sido satisfactorio, Arrupe volvió sobre esta cuestión en repetidas ocasiones. Poco después de su elección señaló que los jesuitas debían trabajar para ayudar a los que sufren la pobreza más extrema y, por otro lado, a los que representan la cultura intelectual más avanzada (Iturrioz, 1965); intuiciones que son el núcleo de la renovación del modelo universitario que estamos estudiando.

La preocupación científica es un rasgo distintivo del carisma jesuita, y tanto Janssens (Carta a toda la universal Compañía acerca de nuestros ministerios) como sus sucesores (Arrupe, 1972b, pp. 239-242; Arrupe, 1982, pp. 282-290) reafirmaron su importancia frente a las tentaciones antintelectuales que golpearon a no pocos jesuitas. Sólo con competencia científica, podrá la Compañía orientar el pensamiento del hombre contemporáneo en el difícil camino hacia Dios. En un segundo momento, es deber de la Compañía "venir en ayuda de todos los que, en cualquier parte del mundo, buscan la solución de estos problemas, para investigar con ellos hasta descubrir cuál es el humanismo que corresponde a un mundo técnico, cuál el verdadero orden social, cuál el sentido de los valores naturales, en qué consiste el ordenado desarrollo de la humanidad, qué sentido debe tener la presencia de la Iglesia y del sacerdote en el mundo de hoy..." (Arrupe, 1972a, p. 272). Desde aquí, llegaría al tercer punto: el ministerio de la educación, desarrollando en las instituciones y alumnos una conciencia social, sobre la que reflexiona, en su carta de 1966 en torno al apostolado social en América (Arrupe, 1972b, pp. 239-242; Arrupe, 1982, pp. 282-290).

Si la Congregación General 31 ya introdujo importantes novedades en torno a lo que se entendía por apostolado social, fue la 32 - precedida por los textos de Pablo VI Octogesima adveniens (1971), Ila- 
mando a los cristianos a comprometerse en la promoción de la justicia, y Evangelii nuntiandi (1975), donde afirmaba la relación interna entre evangelización y promoción de la justicia - la que hace de la promoción de la justicia opción fundamental y núcleo de la misión de la Compañía. Implicaba, acción sobre las estructuras injustas, adecuado análisis de la realidad, revisión de solidaridades y preferencias apostólicas y conversión de estilos de vida (Congregación General 32 de la Compañía de Jesús); algo esencial para explicar la transformación experimentada por las universidades, pues la opción forzó a repensar todos los ministerios y apostolados.

Arrupe insistiría hasta la saciedad en que la tarea educativa jesuita debía consistir en formar hombres para los demás y, reconociendo el tradicional y generoso esfuerzo educativo de la Compañía, en su encuentro con antiguos alumnos en Valencia (1973), dejó claras varias de sus intuiciones: el deber de adaptar la educación a las nuevas necesidades para formar agentes de cambio, reconociendo que "con frecuencia nos quedamos atrás y que a veces todavía estamos formando líderes para una sociedad que ya pasó", y el hecho de que "estamos buscando y experimentando nuevos modelos y fórmulas de educación de tipo más popular" (Arrupe, 1982, p. 361).

Años después, Kolvenbach insiste: "Estoy convencido de que la promoción de la justicia no será efectiva, por parte de nuestra orden, si el sector educativo no se compromete en medida creciente con esta misión. El decreto número 4 de la 32을 Congregación General va en esta línea, aunque pueda haber interpretaciones erróneas del mismo. En él se pide que el apostolado de los jesuitas en el campo educativo se incremente, y subraya su importancia en la formación de los multiplicadores, es decir, de los que pueden actuar para transformar las actitudes de las personas y las estructuras injustas de la sociedad. Por otra parte, no es ciertamente nuestro esfuerzo en el campo educativo lo que se impugna, sino, tal vez, el modo de integrarlo en nuestra misión". Frente al reduccionismo que podría significar la pretensión de enseñar sólo a los más pobres, insiste en que lo realmente importante es enseñar a todos los alumnos "en la perspectiva de la justicia" e introducir la promoción de la justicia dentro de las disciplinas que se enseñan porque todas las disciplinas se pueden enseñar y estudiar con vistas a una liberación humana integral; no hay ninguna enseñanza neutra, es siempre vehículo de valores (Kolvenbach, 1991, pp. 89-92).

\section{CENTROAMÉRICA: EL COMPROMISO COMO FUNDA- MENTO DE LA IDENTIDAD UNIVERSITARIA}

Muchos de los protagonistas, al buscar el acontecimiento central en la transformación de la provincia jesuita centroamericana, significativamente se remiten a los Ejercicios Espirituales que, reuniendo a casi la mitad de los sujetos, se organizaron en diciembre de 1969. (Cardenal, 2009, pp. 59-60) Poco después, al firmar, en Washington, un contrato con el Banco Interamericano de Desarrollo, la USC se autodefine como conciencia crítica y creadora de la realidad salvadoreña dentro del contexto centroamericano, considerando que debe, a partir de una sólida labor científica, diagnosticar la situación, analizar sus causas y proponer soluciones. En este discurso, punto de partida de una reflexión pública, que dura décadas, sobre el sentido de la universidad, se cuestiona abiertamente la idea de desarrollo, citando con insistencia Populorum Progressio, y se introduce un nuevo objetivo: la liberación. (Discurso en la Universidad José Simeón Cañas en la firma del contrato con el Banco Interamericano de Desarrollo) Este mismo año publica Gustavo Gutiérrez, en Lima, Teología de la Liberación y, en las mismas fechas, están apareciendo los primeros textos de esta corriente, que tendrá entre los jesuitas centroamericanos a varios de sus más destacados representantes (Ellacuría, Sobrino, MartínBaro) y que, por supuesto, alimenta la reflexión citada.

Incidiendo en la inspiración cristiana, la urgente dedicación a la transformación histórica de la sociedad y el servicio al pueblo centroamericano, se plantea que la universidad sólo tiene sentido al servicio de las grandes mayorías populares e inserta en una realidad social concreta. El sentido último de una universidad, diría Ellacuría, "debe mensurarse desde el criterio de su incidencia en la realidad histórica, en la que se da y a la que se sirve". (Ellacuría, 1975) De forma semejante se expresarían, con el pasar de los años, César Jerez, José María Tojeira, al hablar de una universidad para el cambio social, comprometida con la utopía, y, en un contexto más amplio, el P. Nicolás, cuando habla de que el punto de partida ha de ser siempre la realidad, desde la cual "buscamos el cambio y la transformación". (Nicolás, 2010) El ideal se ha mantenido a lo largo de los años, modificándose su concreción.

Esta concepción de lo universitario comporta una dimensión política, como servicio a la polis. En modo alguno la politización en la que se caería al enfrascarse en luchas partidarias por el poder, dejarse instrumentalizar por partidos políticos, gobiernos, gremios u oligarquías, y al robustecer el sistema imperante respondiendo a sus demandas, mediante un presunto cultivo neutro del saber y de la técnica. 
Arrupe, recordando Populorum progressio, niega al hombre apostólico la posibilidad de renunciar a toda presencia en lo político, pues tiene la obligación de denunciar claramente lo que contradice la visión del hombre y de la humanidad que la Iglesia tiene como propia. Al tiempo, el jesuita debe estar presente en la política con una función distinta a la del laico y no para sustituir a éste: ha de aportar a la política el testimonio y el anuncio evangélico de salvación, "luces y energías" que "pueden ayudar a constituir y fortalecer la comunidad humana, según la ley divina".

Llevar a la práctica estas ideas no resulta fácil. No faltarán, dice Arrupe, los reproches de parte de aquellos que han comprendido mejor la tragedia de la situación actual y, por eso, tacharán de inconsecuente al jesuita. Además hay dificultades para establecer los límites de la lícita intervención política del religioso "allí donde esté de hecho mermada la justa libertad política" y, así, no sería justo considerar inadmisibles algunos compromisos críticos con el poder establecido. Existen injusticias evidentes frente a las cuales la iglesia no puede tomar una postura neutral sin ponerse de su parte.

Lo está diciendo en España, en mayo de 1970 (Arrupe, $1972 b$, p. 142), pero sus palabras se pueden trasladar a otras circunstancias. De forma semejante se expresa Kolvenbach: "tampoco hoy es fácil, tanto en la teoría como en la práctica, ver las fronteras, ya porque no está siempre claro cuando termina la política en sentido amplio y cuándo comienza la policía partidista, ya porque el concepto de partido tiene significados diferentes según se hable de él en Europa, en América o en África" (Kolvenbach, 1991, pp. 75-78).

Los jesuitas centroamericanos se verán interpelados por este dilema. Saben, como señala ECA en su editorial de noviembre de 1969, que si en muchas ocasiones podría ser prematuro el dictamen, "esto no excusa a iniciar urgentes reflexiones". Saben, también, dice el editorial de abril de 1981, que muchas de las actuaciones y tomas de postura sólo son explicables "en estado de emergencia nacional" y que no habrían sido necesarias si existiesen "los cauces y la libertad para denunciar atropellos y buscar soluciones racionales".

Las universidades centroamericanas tienen claro que el logro de sus objetivos pasa por la autonomía legal, administrativa, académica y de cátedra. Todos los rectores y responsables de estas instituciones han insistido en esta condición, "que trata de convertir una vez más el amor al saber en una fuerza transformadora y reordenadora de la convivencia social". La autonomía "solo tiene sentido si se la vincula con la investigación. Pero con una investigación que se centre en la realidad del propio país y descubra las pistas y caminos que lo pueden llevar a una verdadera transformación. Sin este tipo de investigación amplia, capaz de presionar e incluso forzar ese cambio que va de la injusticia a la justicia... ni la universidad ni la autonomía acaban teniendo sentido. Una universidad que centrara la autonomía en la simple libertad de cátedra puesta al servicio de tareas meramente profesionalizantes acabaría sirviendo a los intereses dominantes... Aportar excelencia profesional es importante y necesario. Pero si la universidad no es al mismo tiempo guía de cómo el saber contribuye a una convivencia en justicia y dignidad puede incluso -en el peor de los casos, claro está- aumentar la barbarie humana" (Tojeira, 2007).

Si la misión está clara - ser conciencia crítica- y la condición necesaria también -la autonomía-, los instrumentos teóricos del éxito son la investigación, la docencia, la proyección social y la democratización de la universidad.

Es fácil leer en muchos universitarios jesuitas centroamericanos una afirmación de Ellacuría, pronto convertida en leitmotiv de toda la misión: No hay conciencia universitaria donde no hay ciencia, porque el saber universitario es un saber científico, riguroso, ejercitado por los mejores talentos y mejor preparados, cada uno en su propia especialización, pero de modo que se alcance un saber organizado y totalizador porque sólo puede cambiarse una estructura social, irracional e injusta, conociéndola a fondo y, para ello, se exige dominar críticamente un conjunto de disciplinas diversas. No se trata de investigar cualquier cosa, encerrada la universidad en una burbuja de autosuficiente elitismo. El compromiso es para con la sociedad donde la institución se inserta, de la que se nutre y a la que sirve. La investigación debe centrarse en todo aquello que conduce a la transformación de las estructuras que posibilitan cualquier tipo de injusticia o exclusión. Para muchos es aquí donde reside la principal diferencia entre una universidad y un centro docente y, aún más, entre las tres universidades fundadas en los años sesenta y las nacidas de la mutación de aquellas.

Hay que mejorar la calidad de los docentes y de la docencia pero con el objetivo de formar hombres para los demás. No cabe limitarse a cualificar buenos profesionales, que no siempre sacan de la universidad la debida conciencia de servicio, antes al contrario, se aprovechan de los medios que ella les proporciona. 
Es también obligación de toda universidad atender a la demanda de quien no puede asistir a sus aulas y las centroamericanas lo han hecho de múltiples formas: programas de educación a distancia, emisoras de radio, publicaciones, periódicas o no, documentales audiovisuales, colaborando en proyectos gubernamentales sobre violencia, política juvenil, seguridad ciudadana o, por ejemplo, capacitación de maestros, etc., y, muy especialmente, a través de la revista ECA. Estudios centroamericanos.

El objetivo ha sido democratizar la enseñanza y la universidad no única, ni principalmente, por la simple admisión de alumnos de menores recursos económicos, aunque se hayan dado esfuerzos en esta dirección, sino por la transformación de los objetivos, los programas y el perfil de los egresados, buscando que éstos sean, con sus profesores, los más comprometidos con la profunda transformación social. Todo este esfuerzo se ha ido concretando en infinidad de actividades a lo largo de los años para mejorar, hacia el interior, la calidad de los docentes y la enseñanza, garantizar la libertad de cátedra y respetar el derecho de las minorías en la universidad, y, hacia fuera, para conocer la realidad, denunciar la injusticia y promover la transformación social. En la práctica, frente al comportamiento de otras universidades centradas en la defensa de sus intereses profesionales y de su autonomía institucional, han multiplicado los pronunciamientos y las denuncias ${ }^{6}$. Más interés tiene considerar las aportaciones científicas publicadas, en monografías o en sus publicaciones periódicas, sobre las cuestiones más diversas de la realidad política, comenzando por el monográfico que la revista ECA dedicó, en noviembre de 1969, al conflicto bélico entre Honduras y El Salvador, a los dedicados, entre otros, a la reforma agraria, en septiembre de 1976, a la política centroamericana de EE.UU., en mayo de 1983, o a las distintas elecciones.

Organizaron oficinas para la defensa política y jurídica de las víctimas de la guerra civil y la represión, como IDHUCA y, en otras ocasiones, los responsables de la universidad se creyeron obligados a participar directamente en política. El caso nicaragüense es el más llamativo, pero también lo hizo el rector de la USC, Román Mayorga, como Presidente de la Junta cívicomilitar en 1979.

Pese a tratarse de tres universidades nacidas en la misma época, integradas en una misma provincia jesuita y fundadas con idénticos objetivos, no cabe ignorar la profunda heterogeneidad de sus evoluciones.
En Managua, pese a la resistencia del equipo rectoral, un sector estudiantil, con apoyo de varios profesores y jesuitas, se movilizó contra Somoza y la represión gubernamental empujó a una mayor identificación con la insurrección. (Cardenal, 2009, pp. 28-43) Triunfante ésta, la UCA inicia una profunda transformación. Convencida de su obligación con la reconstrucción del país y la construcción de un hombre nuevo (La universidad en Nicaragua: una transformación en marcha), optó por integrarse al Consejo Nacional de Educación Superior (CNES), creado en febrero de 1980, y por la educación gratuita financiada por el Estado. Se rompía el modelo elitista de universidad privada y se abrían nuevas perspectivas de compromiso social. La UCA formuló su misión como expresión de una opción preferencial por los pobres a través de un apoyo crítico al proceso de cambio en el país, pero, como reconocería su futuro rector, Xabier Gorostiaga, en realidad, hubo más apoyo que crítica a la revolución (Gorostiaga, 1993). Si fuese preciso probar esto, bastaría con leer los primeros números de la revista Envío, comenzando por su "Presentación". Fue un modelo de universidad ajustado a las necesidades ideológicas y políticas del régimen sandinista y, conociendo los errores de éste, acallaron toda crítica para no favorecer a la contra ni a los intereses estadounidenses (Berryman, 1994, pp. 198-99), en ese sentido se expresa, y lamenta, López Vigil (1991).

La UCA se centró en la formación de funcionarios, cuando la expansión del sector público garantizaba una estable oferta de empleo para los egresados. Aun así, no pudo responder a las necesidades del país y perdió relevancia social por la fuga de profesores, la escasa exigencia académica y los compromisos revolucionarios que llevaron a los alumnos a participar en infinidad de actividades extrauniversitarias. Por mucho que legalmente nada hubiera cambiado en relación a la autonomía decretada en 1959, el CNES recortó seriamente las posibilidades de tener autonomía y de plantearse una tarea académica propia. La autonomía es concebida por la misma UCA "más como una oportunidad de integración al servicio de un proyecto nacional que como un espacio para antagonizar con el poder que rige el país" (La universidad en Nicaragua: una transformación en marcha).

La guerra y las limitaciones impuestas por ésta, tanto de carácter económico - crisis, falta de medios, incomunicación con diversas zonas del país, etc.como ideológico - dificultad para marcar distancia con el sandinismo-, contribuirían a complicar la situación. La integración en un modelo centralizado, 
masificado e impulsado por una mística revolucionaria generó múltiples deficiencias, que fueron ya advertidas durante el gobierno sandinista y claramente analizadas después: bajo rendimiento académico, puesto que la formación quedó en manos de pocos profesionales y de muchos jóvenes que integraron el Movimiento Alumnos-Ayudantes; falta de coordinación entre los múltiples organismos con competencias educativas e indisciplina laboral de profesores y alumnos (véase 50 años de historia de la Facultad de Económicas y Empresariales).

Aunque, para paliar las principales deficiencias, antes de la derrota sandinista se multiplicaron los esfuerzos, centrados en convenios con instituciones internacionales, la situación era gravísima. Es llamativa la ventaja de la USC en múltiples aspectos de gran importancia, por ejemplo, con años de antelación, se ocupó de que la mayoría de sus profesores fueran másteres, si no doctores. Sin renunciar, al tiempo, a ser conciencia crítica de El Salvador. Sus responsables, a raíz de la guerra entre El Salvador y Honduras, y a la par que rechazan análisis que, poco antes, podían encontrarse en la revista ECA (Gómez Díez, 1992), manifiestan simpatía hacia el castrismo y se alejan del desarrollismo a favor de concepciones influidas por la teoría de la dependencia, comenzaron a denunciar las injusticias del sistema político, transformando la universidad.

Este proceso se desarrolló en paralelo a la transformación de las actitudes eclesiásticas y generó pronto una reacción anticlerical conservadora. Ésta primero quiso distinguir entre la Iglesia y algunos de sus sacerdotes radicalizados hacia el marxismo; ECA, en su editorial de mayo de 1974, habla de una nueva iglesia del silencio en los países de América Latina, "donde sus gobernantes se confiesan formalmente católicos", pero rechazan que se predique contra la injusticia y la opresión. En un segundo momento, se rechaza $a$ la Iglesia, al Evangelio y a la verdad, como titularía ECA un editorial a raíz del caso Pellecer, en octubre de 1981; a los asesinatos y expulsiones de sacerdotes y laicos comprometidos se suma una "actitud de prepotencia y desafío contra la Iglesia" como institución, llegando al ataque frontal y al explícito rechazo de su doctrina. Por fin, impúdicamente, el ejército asesinó a la cúpula de la USC.

Antes, en la década de los setenta, la USC no dudó en apoyar los esfuerzos reformistas como camino de construcción de una nueva realidad. Apoyó la reforma agraria del coronel Molina (1972-1977), pese a tratarse de un gobierno militar, fruto de unas elec- ciones fraudulentas y violador de derechos humanos, porque, aunque la reforma fuera parcial e incompleta, podía contribuir a romper la cerrazón de las oligarquías. El régimen de Molina no aguantó la presión de éstas y renunció a la reforma. La USC reaccionó con claridad y manifestó, en varios editoriales de $E C A$, su frustración: "El Salvador se conmueve", julio de 1975, y "A sus órdenes mi capital", diciembre de 1976; las tensiones con el gobierno subieron de tono. Posteriormente, la USC apoyó al golpe de 1979 de la Juventud Militar, incorporándose al gobierno varios de sus dirigentes seglares, incluido su Rector, Román Mayorga. La intención era hacer reformas para evitar la guerra. Antes de un año el gobierno había fracasado, y la USC, en medio del conflicto civil, multiplicó los esfuerzos para alcanzar una paz negociada, criticando tanto al gobierno como al FMLN. Un rápido repaso a la revista ECA pone de manifiesto estos esfuerzos; puede señalarse algún editorial: "Amnistía para El Salvador" (marzo 1978); "Sí hay salida al problema nacional" (abril 1978); "El diálogo en El Salvador como principio de solución política" (noviembre 1982) o el firmado por Ellacuría, "FMLN, el límite insuperable" (diciembre 1985).

Esta actitud reforzó la presencia de la USC en la sociedad y condujo al asesinato de seis jesuitas: un desesperado intento de truncar cualquier solución negociada. Paradójicamente, provocó la reacción internacional y fue un elemento determinante para alcanzar la paz.

Las circunstancias políticas de El Salvador y las sólidas personalidades que regían tanto su iglesia como la USC, impidieron que en esta república se reprodujera el proceso nicaragüense, que puede explicarse, pero plantea una cuestión gravísima: ¿toda acción política en la medida en que pretende ser eficaz, es decir, no reducirse a la crítica de lo establecido, conduce irremisiblemente a un compromiso que amenaza al ser mismo de lo universitario, al debilitar su capacidad para la autonomía? Responder afirmativamente a esta cuestión puede llevarnos a un reduccionismo, pero ignorar esta tendencia sería un error no menor.

Muy distinta fue la situación en Guatemala. Sorprendentemente, en los años 70 la URL se plegó a los reducidos espacios que permitió el poder militar. Hubo algún conflicto, incluso entre los propios jesuitas, y algunos de ellos, como César Jerez, fueron expulsados de la Landívar, que nunca llegó a constituirse en voz crítica frente a la situación de represión, violencia y guerra civil, por mucho que en múltiples ocasiones haya proclamado su compromiso en la búsqueda de 
soluciones a la problemática nacional. Lo significativo es que, mientras la Conferencia Episcopal protagoniza la lucha por los derechos humanos y la URL sigue el proceso de pacificación nacional sin protagonismo alguno, la Compañía manifiesta en diversas ocasiones el mismo espíritu crítico que caracteriza a la USC. En este sentido cabe recordar al Círculo de Jesuitas de la Zona 5, la actividad del P. Falla, la declaración del Provincial, en enero de 1979, donde afirma que en Guatemala domina un sistema de poder anticristiano, que se mantiene con represión, o el Comunicado de la Compañía de Jesús en Centroamérica a propósito de las declaraciones del P. Luis Pellecer, en noviembre de 1981. Sin olvidar a Carlos Pérez Alonso, secuestrado y desaparecido en agosto de 1981, y a Fernando Hoyos, muerto en la guerrilla en 1982.

Lo llamativo no es el compromiso nicaragüense, por mucho que traspase los límites del análisis que sobre la acción política apuntamos arriba y renuncie a la autonomía, convirtiéndose en legitimador del orden establecido, ni el activismo salvadoreño, sino la neutralidad guatemalteca, que sólo puede explicarse considerando las diferencias sociales y políticas entre las repúblicas, la diversidad cronológica, las características de las iglesias nacionales y de la integración en ellas de la Compañía de Jesús y, por supuesto, las personalidades individuales. Es decir, ¿̇cómo contribuye a explicar esta heterogeneidad el hecho de que en Guatemala el porcentaje de indígenas y de evangélicos fuese mucho mayor que en El Salvador o Nicaragua? ¿Cómo lo hace que lo sea el porcentaje de clero nacional en El Salvador y que, en su formación, hayan contribuido decididamente los jesuitas al frente del seminario diocesano? ¿Qué papel juega el episcopado? En este sentido es difícil negar que ni Mons. Casariego ni Mons. Obando estuvieron a la altura de los arzobispos de San Salvador, Chávez y González, Romero y Rivera y Damas. ¿Cómo lo hacen las condiciones políticas de Guatemala, con gobiernos civiles, como el de Vinicio Cerezo desde 1986, una guerra brutal pero alejada del centro de la república, iniciada años antes de que la URL naciera, pero que la guerrilla nunca tuvo posibilidad de ganar? Joaquín Villalobos (integrante del FMLN y negociador de la paz en El Salvador) lo expone con claridad: "La guerra en Guatemala estaba reducida a remotas áreas y esporádicos hechos, no era el principal problema de la sociedad, como sí lo era en El Salvador". (Villalobos, 2000, p. 58) Siendo esencialmente cierta esta tesis, tampoco cabe ignorar que la brutalidad de la represión y la violencia política desatadas por el Estado y el ejército guatemaltecos fueron muy superiores a las vividas en otras repúbli- cas y esto, sumado a los otros factores, pudo hacer conveniente una mayor prudencia. ¿Cómo influye la situación internacional? La radicalización del conflicto es posterior a la llegada de los sandinistas al poder y a la identificación de la UCA con éstos, lo que para muchos fue un error. Por último, ¿qué papel jugaron individuos como Ignacio Ellacuría - al que Juan Hernández Pico atribuye una clarividencia crítica frente a otros jesuitas comprometidos con el sandinismo-, Ignacio Martín-Baró o Segundo Montes?

En la década de los 90, la situación postbélica, la derrota sandinista y el martirio del equipo rector de la USC obligan a abrir nuevos caminos. Entonces sus trayectorias diversas condicionan decididamente la forma en la que cada universidad se autorrepresenta. Sirva como ejemplo el apéndice a la obra de Bianchini, Chinchilla y Romano (2013), donde cada una de las universidades jesuitas americanas responde al apartado "especificidades y sintonía jesuita". La USC, dejando en un segundo plano los aspectos más técnicos y profesionales de su actividad, incide en su historia, en su actividad política y en sus relaciones con el poder; la URL se centra, casi de forma exclusiva, en su actividad docente y en la riqueza de sus laboratorios recientemente ampliados; la UCA, sin ninguna referencia a lo político, insiste en su labor social y en los recientes esfuerzos de las tres instituciones por recuperar el proyecto fundacional de integración centroamericana. En definitiva, quiérase o no, todos debemos lidiar con nuestra propia historia.

\section{LOS AÑOS NOVENTA: AFIRMACIÓN DE LA AUTONO- MÍA Y RECUPERACIÓN DE LA DIMENSIÓN REGIONAL}

Xabier Gorostiaga, por la dificultad de la tarea que le fue encomendada, será clave en esta nueva etapa. De él he podido leer - gracias al P. Hernández Pico- "El Legado de la Experiencia. Centroamérica 1970-2000". Un borrador rico y personal, como lo califica el mismo Pico, quien, además, dándole más valor, lo comenta, corrige y critica. No son unos recuerdos o el esquema de unas memorias; reflexiona sobre su experiencia, centrándose en tres cuestiones: la ambigüedad del compromiso político; factor permanente con el que los cristianos comprometidos tienen que lidiar éticamente; la felicidad que proporciona el compromiso cristiano con los pobres y excluidos y la descomposición moral de las fuerzas progresistas; "la búsqueda del poder por el poder en nombre de la justicia y de los pobres, ha sido la peor corrupción de la izquierda y de la propia Iglesia, al menos en la experiencia de mi vida", dice Gorostiaga. Confirma cómo vincularse 
al sandinismo, fracasado por "personalismo y ambición de poder; corrupción y suicidio ético", empujó a muchos católicos a cometer errores y a la desilusión.

Gorostiaga había colaborado inicialmente con el sandinismo, pero en 1981 renuncia a su cargo, enfrentado al verticalismo político y tecnocrático. "No estaba de acuerdo con lo que se estaba haciendo, dijo, pero seguí apoyando al régimen por la razón fundamental que tenía la revolución sandinista en medio de todos sus errores. $Y$ ante la agresión de Ronald Reagan, yo creí que no había otra opción ética". (Hernández Pico y Marchetti, 2010) En 1991, tras suceder como rector a César Jerez, se propone despolitizar la UCA sin despojarla de su incidencia pública y social, y profundizar su rigor académico. Después trabajaría en la URL y sería secretario ejecutivo de la Asociación de Universidades Jesuitas de América Latina.

Gorostiaga, desde la autocrítica de lo representado por cada universidad, pero con la generosidad de quien, implícitamente, asume que se hizo lo posible o, por lo menos, lo que se creyó debido, va incluso más allá, al insistir en que, frente a la mayoría de los cuadros universitarios, que acaban acomodándose en su función profesional a los condicionamientos del mercado o la política, "las UCA's en Centroamérica en los 70-80 ofrecían una historia diferente, incluso martirial de lucha por la equidad y la justicia social". No obstante, defiende la necesidad de refundar la universidad para enfrentar el reto de la globalización y de un desarrollo humano sostenible. Rechaza la irresponsabilidad intelectual de recurrir a un populismo fácil que culpa al Estado y demoniza al mercado. Lo fundamental es preguntarse ¿qué tipo de universidad hay que construir?; y preguntárselo tras una década, la de los ochenta, perdida económica y socialmente, cuando los niveles de desempleo y pobreza son superiores a los de los peores momentos de la guerra, y la pérdida de riqueza y, peor aún, capital humano ha agravado la brecha con los países más desarrollados, dificultado la inserción competitiva en el mercado internacional y, como consecuencia, profundizado el atraso.

Ahí debe dirigirse la tarea reformista de la universidad, sostenida por un principio básico: "la transformación universitaria sólo puede hacerse en respuesta a los desafíos que existen fuera del recinto universitario". No se pretende imitar la excelencia teórica de las mejores universidades del Norte, sino buscar una excelencia que tenga un carácter aplicado y práctico y sobre todo, una inserción ética de servicio a las grandes mayorías". Así, la tarea es impulsar el desarrollo de capital humano, sin limitarlo, como muchos orga- nismos internacionales, a su vertiente productivista, olvidando el aspecto humano de la formación del carácter y los valores éticos; un capital humano que supere el aislamiento entre docencia e investigación y el aislamiento de ambas tareas académicas con respecto a la sociedad civil; consciente de que no todo es un problema de nuevas técnicas y metodologías, sino de valores y opciones; que partiendo de propuestas nacionales las integre en una visión y destino regional y latinoamericano, y popular, con capacidad de pensamiento alternativo, actualizado y técnico. En definitiva, se trata de un esfuerzo conducente a romper con el fatalismo inducido de que no hay más alternativas que las que otros nos ofrecen.

Con este objetivo, y consciente de que la universidad debe hacer algo más que responder a las demandas del mercado, contribuyendo con propuestas técnicas y científicas que puedan fecundar el desarrollo de toda de la sociedad, establece, recuperando la necesaria autonomía universitaria y rompiendo con actitudes ampliamente extendidas, que el talante universitario que debe sobresalir no es la beligerancia política, sino la beligerancia como institución de educación. Su impacto en la sociedad debe hacerse a través del conocimiento y de la sabiduría, porque hoy el desarrollo y la miseria están definidos en términos de conocimiento y de capital humano (La universidad: preparando el siglo XXI).

Sin ignorar el contexto en el que se ubican estas universidades, al parecer los éxitos están siendo importantes. Se apostó fuerte por los postgrados; se mejoró la calidad de la docencia, incrementando el número de maestros y doctores; se ampliaron las instalaciones y las líneas de investigación; se multiplican los convenios internacionales y la colaboración con la empresa privada; se abrieron, junto a las publicaciones tradicionales, otras líneas de difusión del conocimiento (radioemisoras, audiovisuales, etc.) y se colaboró en proyectos gubernamentales sobre violencia, política juvenil, seguridad ciudadana, reforma educativa, capacitación de maestros, salud pública, vivienda, etc. (Loring, 2010; Cardenal, 2005) Difícilmente se encontrarían testimonios mejores de esta transformación que los números de la revista Enfoque dedicados a los programas de emprendedores en las tres universidades jesuitas de Centroamérica, a la responsabilidad social y al cambio climático, en octubre de 2011, septiembre de 2012 y marzo de 2014.

Todo ello, sin renunciar a ser conciencia crítica, comprometiéndose con el fortalecimiento de la sociedad civil. Hernández Pico (2011), recordando lo pro- 
puesto un año antes por el P. General en su visita a Centroamérica, señala catorce retos relacionados con la pobreza, la convivencia y el desarrollo de la democracia, que la universidad, fortalecida por la memoria de sus mártires y dedicada a formar personas para los demás, debe contribuir a resolver estructurando un plan que permita compartir los frutos de su investigación con las mayorías excluidas. Prolongando una larga tradición, en los últimos años, han hecho pública su opinión sobre las elecciones y sus resultados, los problemas de la emigración, la libertad de prensa, los problemas de violencia e inseguridad, los procesos judiciales contra los responsables de la represión, etc.

\section{CONCLUSIÓN}

Considerando, como recordaba Kolvenbach, que la preocupación por la justicia no es un invento reciente y que tiene una larga tradición en la historia de la Compañía, (Kolvenbach, 1991, p. 92) y la unidad, por lo menos genérica, de criterios y actuaciones del conjunto de las universidades jesuitas americanas "al servicio de la fe y la promoción de la justicia" (Vásquez,
2002, p. 10); lo fundamental sería preguntarse por los resultados del actuar de las universidades jesuitas en Centroamérica. ¿Ha contribuido a hacer de la Iglesia una institución respetada por los sectores en litigio y, así, importante para la resolución de conflictos? ¿Ha incrementado su eco internacional? ¿Ha favorecido la superación de muchos prejuicios con los que la miraban las personas no religiosas? Todo hace pensar que sí. En otro orden de cosas, ¿ha contribuido a mantener su vitalidad y presencia espiritual? También creo posible responder afirmativamente: en el martirio, como ha visto Casas Andrés (2009), el pueblo reconoce la presencia salvadora de Dios; el recuerdo de los mártires se convierte en la memoria agradecida de que Dios no abandonó al pueblo en medio de la precariedad extrema.

Al mismo tiempo, no cabe negar ni la fractura en el seno de la institución eclesial ni el crecimiento de los cultos evangélicos, ni el desarrollo de un antijesuitismo conservador que bien merece ser comparado con el desarrollado, desde posiciones políticas bien distintas, a lo largo del siglo XIX.

\section{NOTAS}

1 Es fácil rastrear este interés, muy especialmente los esfuerzos de los PP. Isidro Iriarte y Carmelo Sáenz de Santamaría, en la documentación del Archivo de la Curia Provincial Jesuita de Centroamérica (ASJ-CA), 11.3 Sujetos de otras Provincias.

2 Claramente lo manifiestan los diversos informes que, a finales de los años sesenta, redactan sus responsables, varios de los cuales se conservan en el Archivo Arzobispal de Guatemala: Correspondencia de la Legión de María y otros grupos de apostolado.
3 Si el clero católico vivió las revoluciones liberales latinoamericanas como una agresión, más cercanas estaban las persecuciones de México y España: no menos del $60 \%$ de los jesuitas que trabajaban en Centroamérica al comenzar la década de 1960 las había sufrido.

4 Al ser elegido General, el P. Arrupe encargó a todas las provincias y viceprovincias independientes de la Compañía un estudio sobre su situación. Los doce volúmenes del Survey de Centroamérica (1969 - 1970) los pude consultar en ASJ-CA. Para la cuestión educativa son especialmente útiles los volúmenes IV La financiación de los Colegios y su consiguiente clasismo, y VIII Apostolado de los Colegios, aparte del III (Análisis de los recursos humanos), X (La formación de los jesuitas) y XI (De cara al futuro).

5 ASJ-CA: Viceprovincia dependiente. Informes anuales a Roma; 19, VII, 1949.

6 No tiene sentido insertar citas para probar algo que resulta evidente en una rápida consulta a la revista $E C A$ o a las páginas web de las universidades jesuitas de Centroamérica.

\section{BIBLIOGRAFÍA}

Arrupe, P. (1972a). Nuestra vida consagrada. Madrid: Hechos y dichos.

Arrupe, P. (1972b). Escala en España. Madrid: Apostolado de la prensa.

Arrupe, P. (1982). La Iglesia de hoy y del futuro. Bilbao-Santander: MensajeroSal Terrae.

Berryman, P. (1994). Stubborn Hope. Religion, Politics, and Revolution in Central America. New York: Orbis Books.
Bianchini, P., Chinchilla, P. y Romano, A. (2013). De los colegios a las universidades. Los jesuitas en el ámbito de la educación superior. México: Universidad Iberoamericana-Universidad Javeriana.

Cardenal, F. (2009). Junto a mi pueblo, con su revolución. Madrid: Trotta.

Cardenal, R. (2005). La UCA 40 años después. ECA. Estudios Centroamericanos, 60, 685-686, pp. 1041-1050.

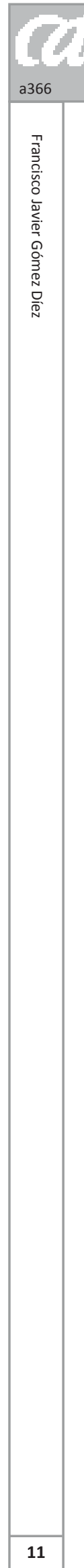

Casas Andrés, R. (2009). Dios pasó por EI Salvador. La relevancia teológica de las tradiciones narrativas de los mártires salvadoreños. Bilbao: Desclée de Brouwer.

Consejo Superior Universitario de la USC (1973). Declaración. ECA. Estudios Centroamericanos, 28, 297, pp. 523-526.

Ellacuría, I. (1975). Diez años después, ¿es posible una universidad distinta? ECA. Estudios Centroamericanos, 30, 324325, pp. 605-628. 
Gómez Díez, F. J. (1992). El reformismo jesuítico en Centroamérica: la Revista ECA en los años de la Guerra Fría (19461965). Suplemento del Anuario de Estudios Americanos, 49, 1, pp. 85-105.

Gómez Díez, F. J. (1996). La Viceprovincia Dependiente de Centroamérica de la Compañía de Jesús. Miscelánea Comillas, 54, 104, pp. 93-115.

Hernández Pico, J. y Marchetti, P. (2010). «Organizando la esperanza». Xabier Gorostiaga: una vida en el apostolado internacional. Enfoque, 19, pp. 1-6.

Hernández Pico, J. (2011). El quehacer hoy de la Universidad Centroamericana y las actitudes que propician la esperanza de emprenderlo. ECA. Estudios Centroamericanos, 66, 724, pp. 37-44.

Iturrioz, J (1965). La Congregación General XXXI de la Compañía de Jesús. Razón y $\mathrm{Fe}, 65,810-811$, pp. 71-82.

Kolvenbach, P. H. (1991). Fieles a Dios y al hombre. Madrid: Ediciones Paulinas.

López Vigil, M. (1991). La realidad de la iglesia de los pobres en Nicaragua. En: Gorostiaga, X. (ed.). Dando razón de nuestra esperanza. Los cristianos latinoamericanos frente a la crisis del socialismo y la derrota sandinista. Managua: Nicarao, pp. 76-82.
Loring, J. (2010). Un proceso renovador de 29 años. Enfoque, 19, p. 19.

Mantilla, S., (1965). En El Salvador se inaugura una universidad privada. ECA. Estudios Centroamericanos, 20, 209, pp. 253-256.

Nicolás, A. (2010). Discurso al Congreso Internacional de Instituciones de Educación Superior de la Compañía de Jesús. "Creación de redes sociales en la Educación Superior Jesuita". En: Margenat, J. M. (ed.). Competentes, conscientes, compasivos y comprometidos. Madrid: PPC, pp. 173-196.

O’Malley, J. W. (1993). Los Primeros Jesuitas. Bilbao-Santander: Mensajero-Sal Terrae.

Tojeira, J.M. (2007). Discurso durante la entrega de la acreditación a la UCA. ECA. Estudios Centroamericanos, 62,709710, pp. 103-107.

Valero Agúndez, U. (2012). El proyecto de renovación de la Compañía de Jesús (1965 - 2007). Bilbao-Santander: Mensajero-Sal Terrae.

Vásquez, C. (2002). Proceso de Construcción de una Identidad Ignaciana. En Rico, C. (comp.). Desafíos de las Universidades Jesuitas en América Latina: La identidad ignaciana. Montevideo: Universidad Católica del Uruguay, pp. 7-19.
Villalobos, J. (2000). Sin vencedores ni vencidos. San Salvador: Instituto para un nuevo El Salvador (INELSA).

\section{Recursos de Internet}

Gorostiaga, X. (1993). La universidad: preparando el siglo XXI. Envío, 138. [en línea] [consultado: 8 de mayo de 2014] Disponible en: http://www.envio.org. ni/articulo/792

La universidad en Nicaragua: una transformación en marcha (1986) Envío, 57. [en línea] [consultado: 26 de abril de 2014] Disponible en: http://www.envio.org. ni/articulo/482

\section{Otras fuentes}

Compañía de Jesús. (1975). Congregación General 32. Madrid: Razón y Fe.

Discurso en la Universidad José Simeón Cañas en la firma del contrato con el Banco Interamericano de Desarrollo (27 octubre 1970). ECA. Estudios Centroamericanos, 26, 268, 1971, pp. 108-112.

Janssens, J. B. (1947). Carta a toda la universal Compañía acerca de nuestros ministerios. Oña.

50 años de historia de la Facultad de Económicas y Empresariales. Enfoque, 19, 2010. 